\title{
Non-communicable disease pattern in adults seeking preventive general health checkup
}

\author{
Bikash Shrestha ${ }^{1}$, MD; Bipin Nepal², MD; Ravi Mahat ${ }^{3}$, FCPS; Abish Adhikari ${ }^{4}$, MD \\ ${ }^{1}$ Department of Wellness \& Family Medicine, Grande International Hospital, Kathmandu, Nepal \\ ${ }^{2}$ Department of Transfusion Medicine, Grande International Hospital \\ ${ }^{3}$ Department of Pulmonology, Grande International Hospital \\ ${ }^{4}$ Department of Oncology, Grande International Hospital
}

Corresponding author

Bikash Shrestha, MD

Email: shrestha811@gmail.com

Received 10 Dec 2018

Accepted 20 Dec 2018

\section{ABSTRACT}

Non Communicable diseases (NCDs) are now endemic in low and middle income countries. Nepal had a high burden of communicable diseases (CDs) which has now been overtaken by NCDs. Although prevention and control of NCDs is prioritized in national policies and strategies, there is no proper monitoring system. This study aims to review the morbidity pattern among the adults seeking preventive general health checkup in a major tertiary care hospital in Kathmandu. 3000 cases were evaluated. $53.6 \%$ were males and $46.4 \%$ were females. The mean age of cases was 44.9 yrs. Most of the cases ranged from 40 to 60 years of age. Almost half of them were from Kathmandu district. Nearly $78 \%$ participants live a sedentary life. Abdominal obesity was seen in $27.5 \%$ of females and $21.7 \%$ of males. Nearly $49 \%$ of cases were overweight and $24 \%$ were obese. Almost $21 \%$ of the cases were smokers and about $36 \%$ of them consumed alcohol. Only $9 \%$ are vegetarians. $10 \%$ have diabetes and $20 \%$ have hypertension. $69 \%$ of females and $43 \%$ of males have less than normal bone mineral density.

The government and private sectors must focus on strengthening preventive and curative services for early detection of risk factors and management of NCDs.

\section{Introduction}

Non-communicable diseases (NCDs) are conditions for which transmittable causative agents are not known but have associated risks like change in lifestyle, genetic and environmental factors ${ }^{1}$. Previously regarded as a burden of the developed countries, NCDs are now endemic in low and middle income countries. Globally, NCDs accounts for large proportion of morbidity and mortality ( $68 \%$ of all deaths) $)^{2}$. Globalization and urbanization has brought changes in lifestyle of the people with Nepal being no exception. Nepal had a high burden of communicable diseases (CDs) which has now been overtaken by the increasing age-standardized death rates and disability adjusted life years by NCDs. In Nepal, $44 \%$ of deaths are attributed to $\mathrm{NCDs}^{3}$. Hypertension is seen in $27 \%$ of the population ${ }^{4}$, diabetes in 12 $15 \%^{1-5}$. NCDs risk factor survey done estimated the prevalence of overweight at about $7 \%$ and that of obesity at around $1.7 \%{ }^{6}$. Cost effective interventions to change the lifestyle like keeping oneself active, eating balanced and healthy diet, avoiding tobacco (in any form) and alcohol have proven to decrease the burden of NCDs around the world causing reduction of cardiovascular and diabetes by $80 \%$ and cancer by $40 \%{ }^{7}$.

Although Nepal has taken steps for the prevention and control of NCDs with national policy in $2009^{8}$ and strategy and plan of action in $2014^{9}$, there is no proper monitoring system. This study aims to review the morbidity pattern among the adults 
attending preventive general health checkup in a major tertiary care hospital in Kathmandu.

\section{Method}

A cross sectional, quantitative descriptive study was done in Grande International Hospital, Department of Family Medicine and Wellness Center. Grande International Hospital is a major tertiary care hospital in Kathmandu which gives equal importance to preventive aspect of health care. People come to the department as they become more aware of chronic NCDs like diabetes, hypertension, and cancers. Three thousand case sheet data were obtained by non-probability sampling (purposive sampling technique) from the questionnaire filled by/for the people who came for general health checkup from June 2016 to December 2017. To avoid selection bias, all the participants were enrolled in the study. People above 16 were included in the study. The variables assessed were age, gender, address and morbidities like diabetes, hypertension, dyslipidemia, obesity, physical activity status, smoking, and alcohol use status. Descriptive statistical analysis was performed using SPSS version 16 (SPSS Inc. in Chicago).

\section{Results}

A total of 3000 contiguous file records of patients visiting the wellness center at Grande International Hospital were analyzed, out of which 1609 (53.6\%) were males and 1391 (46.4\%) were females. The mean age of cases was 44.9 yrs. Maximum cases belonged in the age group of $60-79$ years $(46 \%)$ followed by $40-59$ years $(40.1 \%)$. Nearly $86 \%$ of the participants were married. Top 5 districts from where they came for general health checkup were Kathmandu (47.2\%), Kaski (6\%), Rupandehi (4.9\%), Chitwan (2.6\%) and Lalitpur (2.3\%).

Physical activity was analyzed according to the World Health Organization scoring and divided into moderate intensity and vigorous intensity. In our study, nearly $78 \%$ participants were living sedentary life (light physical activity). Only $21.6 \%$ were doing moderate intensity physical activity in daily life. BMI was calculated and significant proportion of the cases was found to be out of the normal range. Abdominal obesity was seen in $27.5 \%$ of females and $21.7 \%$ of males. Distribution of Body Mass Index showed that nearly $49 \%$ of cases were overweight and $24 \%$ were obese.

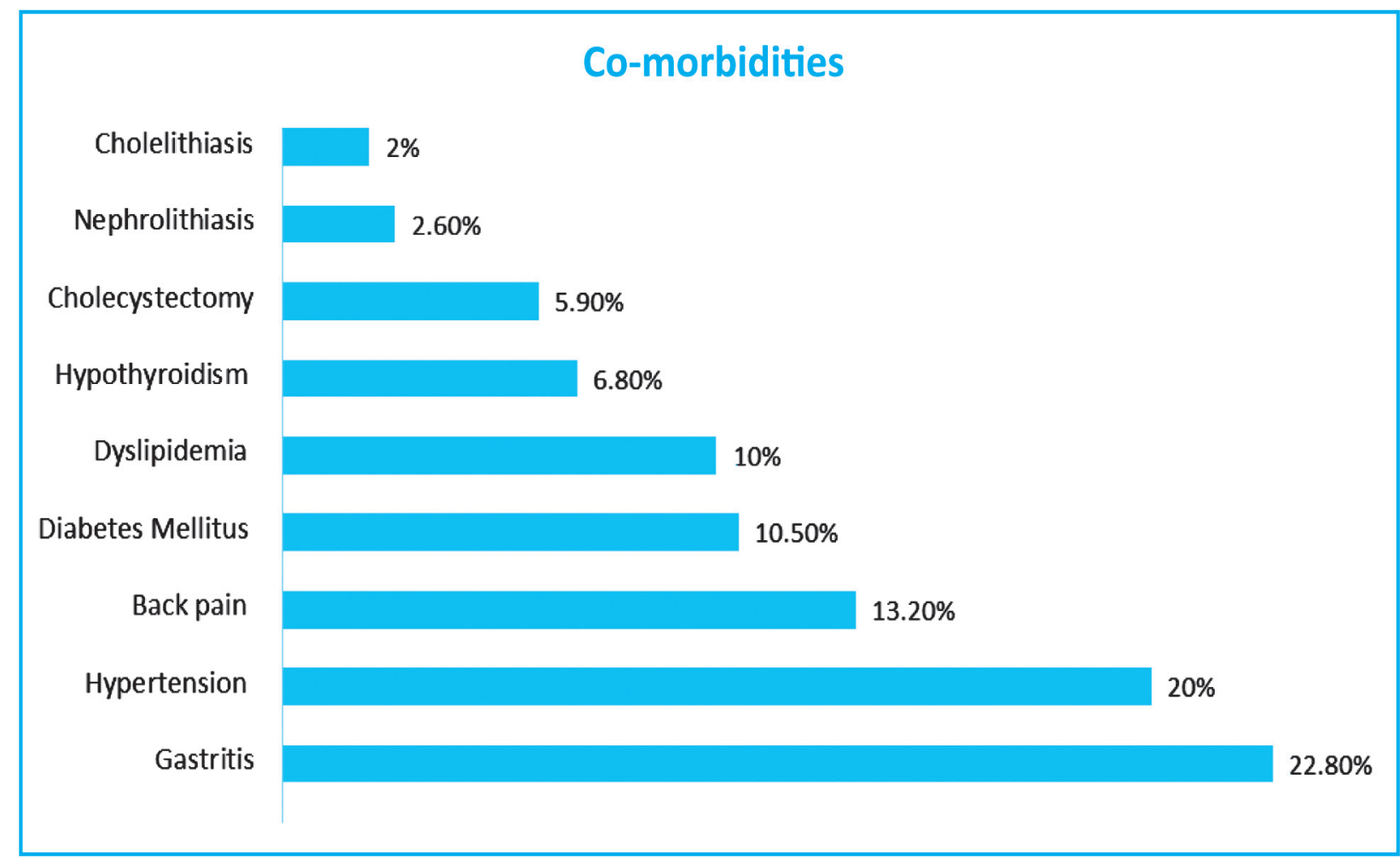

Figure 1: Incidences of Various Co-morbidities in the 3000 cases evaluated. 
Self-declared smoking status was evaluated and it was found that almost $21 \%$ of the cases were smokers, amongst whom, $83 \%$ were males. Almost $36 \%$ of the cases consumed alcohol. Males constituted $84 \%$ of alcohol consumers. Only $9 \%$ of our cases identified themselves as vegetarians.

Other co-morbidities were analyzed and presented in the chart below.

Out of 383 participants who had undergone bone mineral density test, 170 (44.4\%) had osteopenia and $70(18.3 \%)$ had Osteoporosis. Both osteopenia and osteoporosis were seen more in females.

Table 1: Sex Distribution of Findings of BMD.

\begin{tabular}{|l|r|r|r|}
\hline \multicolumn{1}{|c|}{ BMD } & \multicolumn{1}{c|}{ Female } & \multicolumn{1}{c|}{ Male } & \multicolumn{1}{c|}{ Total } \\
\hline Normal & $89(30.9 \%)$ & $54(56.8 \%)$ & 143 \\
\hline Osteopenia & $136(48.2 \%)$ & $34(35.8 \%)$ & 170 \\
\hline Osteoporosis & $63(21.9 \%)$ & $7(7.4 \%)$ & 70 \\
\hline Total & $288(100 \%)$ & $95(100 \%)$ & 383 \\
\hline
\end{tabular}

\section{Discussion}

Variability in methods applied across various studies and unavailability of reliable data on NCDs prevalence in many countries has made cross country comparisons difficult ${ }^{1,2}$. However, this hospital based study will provide information for similar further studies estimating the burden in the population.

In this study, obesity is seen in $22.3 \%$ of cases. Among the obese, the proportion was significantly higher in females compared to males $(60.3 \%$ vs $39.7 \%$ ) which is similar to the findings seen in a survey done by ministry of health and population in $2007^{10}$. Central Obesity is also seen more in female. Among females, $59.3 \%$ cases had central obesity compared to $40.5 \%$ among male cases. Relative sedentary lifestyle is one of the possible reasons as it is prevalent in nearly $90 \%$ among urban women in Kathmandu ${ }^{6}$.

In this study, hypertension was present in nearly $20 \%$ of cases. Previous studies had reported the prevalence of hypertension ranging from $22.4 \%$ to $38.6 \%^{3}$. A study done by Vaidya et al. reported a threefold rise in prevalence of hypertension in Nepali population over 25 years $^{11}$. Similar prevalence of hypertension has been reported in studies done by Vaidya et al. and Chataut et al..$^{11,12}$.

Various studies done in Nepal reported burden of diabetes mellitus ranging from $4.1 \%$ to $9.5 \%$ which were less than the result from this study $(10.5 \%)^{13}$. ${ }^{17}$. However, nationwide survey showed prevalence of $14.6 \%$ in urban areas and $2.5 \%$ in rural areas ${ }^{5}$. Male gender showed higher prevalence than female in previous studies which was similar in this study as well ${ }^{14-16}$.

Dyslipidemia is one of the important risk factors for cardiovascular disease. A study done by Kalra et al. observed the prevalence of hypercholesterolemia to be $12.6 \%{ }^{18}$. A WHO STEPS survey done in 2013 for NCDs in Nepal showed that the prevalence of raised total cholesterol to be $22.7 \%$ and that of triglyceride to be $25.2 \%$. The prevalence was found to be more in males in both ${ }^{19}$.

In the present study Osteoporosis was seen in $18.3 \%$ cases and osteopenia in $44.4 \%$ cases among those who had done bone mineral density (383 cases). Among Osteopenia the proportion of female was $80 \%$ and male was $20 \%$. The proportion for osteoporosis was even higher with $90 \%$ in females and $10 \%$ in males. Osteoporosis was seen more in age group more than 60 years. The bone mineral density (BMD) peaks at about 35-years of age and then begins to decline with advancing age. Significant deceleration of BMD is seen in females after menopause $\mathrm{e}^{20}$. These conditions increases bone fragility and risk of pathological fractures especially of hips and spine thereby compromising quality of life if the fracture occurs.

History of cholecystectomy was observed in about $6 \%$ of cases. Similar ratio was seen in the studies done by Jaisawal et al. $(1: 2.3)^{21}$ and Pradhan et al. $(1: 3)^{22}$. The risk of cholelithiasis is higher when there are aggravating factors like physical inactivity, obesity and diabetes. Higher proportion of obesity and lack of physical inactivity in the present study might be the cause of cholelithiasis followed by cholecystectomy.

The percentage of smokers and alcohol consumers has decreased in the past 3 STEPS survey ${ }^{3}$. In the STEPS survey 2013 the prevalence of smoking was $18.5 \%$ where the proportion of males was more than females ${ }^{19}$ which was similar to the findings of present study. However, the prevalence of alcohol consumption at present was $36 \%$ (males $56.7 \%$, females $12.1 \%$ ) which is more than the findings 
see in STEPS survey 2013 (total 17.4\%, males 28\%, females $7.1 \%)^{19}$. Although, decreased prevalence of low level physical activity was seen in STEPS survey 2008 to 2013 (5.3\% in 2008, 3.5\% in 2013) the present study showed high prevalence of low level physical activity (light activity) (78.2\%) among the cases with almost equal proportion in both the genders. However, the ratio of male: female was 2.7:1 among those who did moderate level physical activity.

\section{Conclusion}

Non-communicable diseases have become a significant public health problem even in developing country like Nepal in addition to the burden of communicable diseases. There seems to be the huge gap between the theory of policy making and practical implementation of plan of action. Simple and cost effective lifestyle change measures like healthy eating habit, regular physical activity, avoiding tobacco and alcohol can decrease the risk of acquiring the disease and improve the quality of life. The government and private sectors must focus on strengthening preventive and curative services for early detection of risk factors and management of NCDs.

\section{References}

1. Bhandari GP, Angdembe MR, Dhimal M, Neupane $\mathrm{S}$, Bhusal C. State of non-communicable diseases in Nepal. BMC Public Health. 2014;14:23.

2. WHO (2014) Global status report on noncommunicable disease $2014 . \quad$ Geneva: World Health Organization. Available at http://apps.who.int/iris/bitstream/handle/ 10665/148114/9789241564854_eng.pdf

3. Mishra SR, Neupane D, Bhandari PM, Khanal $V$, Kallestrup P. Burgeoning burden of noncommunicable diseases in Nepal: A scoping review. Global Health. 2015;11:32.

4. Neupane D, McLachlan CS, Sharma R, Gyawali B, Khanal V, Mishra SR, et al. Prevalence of hypertension in member countries of South Asian Association for Regional Cooperation (SAARC): Systematic review and meta-analysis. Medicine. 2014;93(13):e74.

5. Singh DL, Bhattarai MD. High prevalence of diabetes and impaired fasting glycaemia in urban Nepal. Diabet Med. 2003;20(2):170-1.

6. Vaidya A, Shakya S, Krettek A. Obesity prevalence in Nepal: Public health challenges in a low-income nation during an alarming worldwide trend. Int J Environ Res Public Health. 2010;7(6):2726-44.
7. Epping-Jordan JE, Galea G, Tukuitonga C, Beaglehole R. Preventing chronic diseases: taking stepwise action. Lancet. 2005;366(9497):1667-71.

8. Ministry of Health and Population Government of Nepal (2009). Integrated non-communicable diseases(NCDs) preventionandcontrol policyofNepal. Available at: https://www.iccp-portal.org/system/ files/plans/integrated_non-communicable_ diseases_ncds_prevention_and_control_policy_ of_nepal.pdf

9. Gautam R. NCDs in Nepal: Burgeoning burden amid low priority and the ways forward. Health Prospect. 2012;11:iv-v.

10. Ministry of Health and Population Government of Nepal (2008); Non-communicable diseases risk factors survey 2007/2008. Available at: http://library.nhrc.gov.np:8080/nhrc/bitstream/ handle/123456789/147/601.pdf

11. Vaidya A, Pathak RP, Pandey MR. Prevalence of hypertension in Nepalese community triples in 25 years: A repeat cross-sectional study in rural Kathmandu. Indian Heart J. 2012;64(2):128-31.

12. Chataut J, Adhikari RK, Sinha NP. The prevalence of and risk factors for hypertension in adults living in central development region of Nepal. Kathmandu Univ Med J (KUMJ). 2011;9(33):13-8.

13. Baral N, Koner BC, Karki P, Ramaprasad C, Lamsal M, Koirala S. Evaluation of new WHO diagnostic criteria for diabetes on the prevalence of abnormal glucose tolerance in a heterogeneous Nepali population-The implications of measuring glycated hemoglobin. Singapore Med J. 2000;41(6):264-7.

14. Pokharel D, Gautam N, Archana J, Nagamma T, Kumar R, Sapkota RM. Frequency of Type 2 diabetes mellitus and impaired glycemia in a teaching hospital of South-Western Nepal. Asian J Med Sci. 2012;2(3);202-6.

15. Karki P, Baral N, Lamsal M, Rijal S, Koner BC, Dhungel $S$, et al. Prevalence of non-insulin dependent diabetes mellitus in urban areas of eastern Nepal: A hospital based study. Southeast Asian J Trop Med Public Health. 2000;31(1):163-6.

16. Ono K, Limbu YR, Rai SK, Kurokawa M, Yanagida J, Rai $G$, et al. The prevalence of type 2 diabetes mellitus and impaired fasting glucose in semiurban population of Nepal. Nepal Med Coll J. 2007;9(3):154-6.

17. Paudyal G, Shrestha MK, Meyer JJ, Thapa R, Gurung $R$, Ruit $S$. Prevalence of diabetic retinopathy following a community screening for diabetes. Nepal Med Coll J. 2008;10(3):160-3. 
18. Kalra S, Narain S, Karki P, Ansari JA, Ranabhat K, Basnet N. Prevalence of risk factors for coronary artery disease in the community in eastern Nepal--A pilot study. J Assoc Physicians India. 2011;59:300-1.

19. WHO (2013) Non communicable diseases risk factors: STEPS survey Nepal 2013. Geneva: World Health Organization. Available at www.searo. who.int/nepal/mediacentre/non_communicable_ diseases_risk_factors_steps_survey_nepal_2013. pdf.

20. Lamichhane AP. Osteoporosis - An update. JNMA J Nepal Med Assoc. 2005;44(158):60-6.
21. Jaisawal RK, Mishra C, Panthee MR, Pathak YR, Acharya AP. Prevalence of gall stone disease in Nepal: Multi center ultrasonographic study. Postgraduate med j National academy of Med Sci. 2007;7(2):45-50.

22. Pradhan SB, Joshi MR, Vaidya A. Prevalence of different types of gallstone in the patients with cholelithiasis at Kathmandu Medical College, Nepal. Kathmandu Univ Med J. 2009;7(27):286-71. 